Article

\title{
Rhythmanalysis of Urban Events: Empirical Elements from the Montreux Jazz Festival
}

\author{
Guillaume Drevon ${ }^{1, *}$, Luca Pattaroni ${ }^{1}$, Lucien Delley ${ }^{1}$, Fabien Jacot-Descombes ${ }^{1}$ and Nils Hamel ${ }^{2}$ \\ ${ }^{1}$ Urban Sociology Lab, Swiss Federal Institute of Technology Lausanne, 1015 Lausanne, Switzerland; \\ E-Mails: guillaume.drevon@epfl.ch (G.D.), luca.pattaroni@epfl.ch (L.P.), lucien.delley@epfl.ch (L.D.), \\ fabien.jacot-descombes@epfl.ch (F.J-D.) \\ ${ }^{2}$ Digital Humanities Lab, Swiss Federal Institute of Technology Lausanne, 1015 Lausanne, Switzerland; \\ E-Mail: nils.hamel@epfl.ch \\ * Corresponding author
}

Submitted: 21 February 2020 | Accepted: 1 June 2020 | Published: 30 June 2020

\begin{abstract}
This article proposes an original approach to urban events mapping. At the theoretical level, the article is based on rhythmanalysis and recent research on urban rhythms. It contrasts with previous research by departing from everyday rhythms to tackle the specific rhythms of urban events. Drawing on this theoretical framework, the article proposes to analyse the rhythms of the Montreux Jazz Festival. The article proposes two main types of rhythmic scales, linked with the historical development of the Festival and its annual performance. The methodology is based on a mixed method of data collection and an original analysis framework. The analysis of the historical rhythm is carried out based on the analysis of the festival archives and interviews with experts. The analysis uses the Time Machine visualisation device that reveals three processes of urban resonance: the spread, which shows how the festival is integrated into the existing urban fabric; the openness, which shows accessibility; and the grip, which seeks to evaluate the urban sphere of influence of the event. These different visualisations are enriched by the addition of other data, including ticket scanning and commercial transactions that show the alternance between high and low-intensity periods. These allowed us to not only confirm the impact of programming on flows, but also the effects of the wider organisation of the leisure system. The results of the analysis show that the intertwining of the two rhythmic scales produces a hyper-place that resonates both internationally and locally.
\end{abstract}

\section{Keywords}

eventful city; GIS; hyper-place; mobility; Montreux Jazz Festival; rhythmanalysis; rhythmic scales; Time Machine; visualisation

\section{Issue}

This article is part of the issue "Territories in Time: Mapping Palimpsest Horizons" edited by Chiara Cavalieri (UCLouvain, Belgium) and Elena Cogato Lanza (EPFL, Switzerland).

(C) 2020 by the authors; licensee Cogitatio (Lisbon, Portugal). This article is licensed under a Creative Commons Attribution 4.0 International License (CC BY).

\section{Introduction}

During their development, large public events lead to major yet temporary reconfigurations of urban forms, whether in the use of buildings and public spaces, flows, or even individual and collective behaviour (Boullier, 2015; Viot, Pattaroni, \& Berthoud, 2010). However, their resonance often extends beyond the time of their perfor- mance through the constitution of various institutional, memorial, and spatial traces that might modify dominant "urban assemblages" (McFarlane, 2011). In the case of a festival like the one in Montreux, which is at the heart of this article, the development and reputation of the city have gradually been merged-symbolically and spatially - with the development and reputation of the event. At each rehearsal, the festival's sphere of influ- 
ence extends over the city, through new buildings or the expansion of parts of the city affected by the flows of visitors and the multiplication of stages. This integration of a public event into the urban fabric and life of a city can be compared, in an urban planning point of view, as the active production of what Michel Lussault calls a "hyper-place" that functions "intensively at all political and spatial scales at the same time, from local to global" (Lussault, 2017). In this perspective, this article does not focus on stabilised everyday life rhythms, as the majority of recent urban rhythms researches. It claims the necessity to account for the spatial and temporal reconfiguration of urban rhythms induced by temporary large events that have strong and often lasting effects on ordinary city fabric and life. To respond to this conceptual challenge, we propose to use the conceptual framework of rhythmanalysis, which allows both the analysis of the rhythms of growth of the festival throughout history and the urban rhythms analysis during the period of the festival.

In the first part of the article, we develop the concept of 'rhythmic scale' to suggest the active interpenetration of temporal and spatial elements; any urban rhythm scaling up its material and immaterial territory. In the second part, we offer a narrative analysis of the transformation of the Festival and Montreux as a hyper-place through its careful branding and the increased intensity of the event. The following parts are dedicated to the analysis and visualisation of the rhythmic scales of the Festival. After tackling the methodological stakes of the research and the data we use, we offer the first set of visualisations of the historical rhythmic scales of the event, measuring among other the evolution of the openness, spread, and grip of the festival. The annually collected data allow for the use of the EPFL "Time Machine," and its linear rhythmic visualisation, to show the transformation of the grip of the Festival on the urban context. The last part of the article offers some statistical analysis of the performance rhythmic scales especially through the variation of public attendance.

\section{Background}

\subsection{Rhythmic Approaches and Urban Rhythms}

Henri Lefebvre's work has inspired many works in Sociology over the past 20 years, as evidenced for example by the recent publication of the Routledge Handbook of Henri Lefebvre, The City and Urban Society (Leary-Owhin \& McCarthy, 2019). Within Henri Lefebvre's extensive work, rhythmanalysis (Lefebvre, 1992) constitutes a major contribution to the field of urban studies, particularly in sociology and geography. To situate our perspective, it is important to briefly present the main trend of the vast literature inspired by rhythmanalysis. Among other, rhythmanalysis has inspired many studies and scholars on the analysis of daily activity programmes (Axhausen, Zimmermann, Schönfelder, Rindsfüser, \& Haupt, 2002; Ellegård \& Vilhelmson,
2004; Hallin, 1991), management of daily time balance (Rosengren, 2019), analysis about the transformation of social and political relations (Hassan, 2007), acceleration of mobility (Bauman, 2013; Drevon, Kaufmann, \& Gerber, in press; Viry, Ravalet, \& Kaufmann, 2015), life rhythms (Kristensen, 2018; Rosa, 2013), body experience in public space (Edensor, 2012; McCormack, 2014; Simpson, 2008), and territorial times (Klein, Drevon, \& Gwiazdzinski, 2017; Mareggi, 2013; Pradel, 2010).

As suggested by this non-exhaustive list, rhythmanalysis is not yet a well-defined field of research and science of rhythms is yet to be founded (Brighenti \& Kärrholm, 2018). As Brighenti and Kärrholm (2016) claim, such science of rhythms could be integrated into a general science of the processes of territorialisation and socialisation (Brighenti \& Kärrholm, 2016; Kärrholm, 2007) by putting into perspective the melodies and refrains revealed by the deployment of daily activities that take place with varying degrees of intensity (Brighenti \& Kärrholm, 2018).

In this perspective, the literature that advocates a rhythmic approach proposes to take into account both the spatio-temporal shapes of rhythms as suggested, for example, by time-geography (Lenntrop, 1976; Pred, 1977) and the social interactions generated by periods of social synchronisation (Launay, Tarr, \& Dunbar, 2016). The association between the shapes of rhythms and the social relationships that result from them tend to reify places and define different forms of territoriality (Edensor, 2012; Mels, 2016). This perspective refers in particular to Henri Lefebvre's approach to the production of space, which depends on the location in time and space of social relations and their intensities (Lefebvre, 1974).

Other work on the relationship between rhythm and territory also suggests that rhythm is a powerful way of reducing the social and cultural tensions generated at the territorial level by demographic pressures such as tourism. In this perspective, rhythm becomes a tool for regional planning and a lever for public policies. Indeed, the regulation of rhythms through restrictions is likely to redistribute the different forms of affluence in time and space and consequently reduce pressures on territories (Flemsæter, Gundersen, Rønningen, \& Strand, 2019). This original approach to rhythm regulation calls for a broader reflection on a rhythm policy that would tend to limit pressures on environments and individuals (Antonioli, Drevon, Kaufmann, Gwiazdzinski, \& Pattaroni, 2020).

As we see here, a large proportion of current research is mainly concerned with daily social and urban rhythms. Approaches that propose a rhythmanalysis of urban events are rarer. However, recent works (Antchak, 2018; Edensor \& Larsen, 2018) show the interest of analysing urban events using the concept of rhythm to put into perspective the deleterious effects of strong rhythmic pressures on territories and the need to regulate and manage major events. The article positions itself in the continuation of those works by proposing a 
rhythmanalytic approach to the Montreux Jazz Festival and large urban events. Nevertheless, even though we shift the focus of the analysis, we also consider rhythms as a central feature of both territorialisation and coordination processes.

\subsection{Events Resonance, Traces, and Rhythmic Scales}

A rhythmic approach of large urban events requires descriptive and analytical tools allowing to account not only for the temporary social and spatial reconfigurations whilst the event is happening, but also for the larger changes in urban forms and usages that it induces over time and space (Viot et al., 2010). Indeed, the performance of any public event implies important "investment in forms" (Thévenot, 1984)-such as public justifications, planning, security protocols, spatial settingswhere it finds its political legitimacy and practical layout. Those investments are essential as events are potentially disruptive of daily routines and urban assemblage. They need on the contrary to be carefully framed and regulated in order to confer them their expected qualities, be it in terms of intensity, security, profitability, or hospitality. In other words, the expected outcomes and qualities of any large events stem from their active "enrolment" to borrow the terms of actor-network theory (Callon, 1986) - in the broader mechanisms of social and spatial (re)production of urban order. It is in the constitution of this broader scope and territory of the event that it acquires its rhythmic complexity.

We use the term resonance to subsume the different ways a specific event produces spatial and temporal effects under one concept-the multiple connections it constitutes while it is performed and the traces it leaves over time. Those traces can be material, as is the case of remaining infrastructures produced to host a large event, or they can also lay in memories as the recursive and haunting narratives of the fire that destroyed the Montreux Casino in 1973. But there are still many more types of traces such as the various security protocols, spatial regulations, or institutional innovations that are transmitted through the years. Hence, resonance and traces are about how the performance of one large event has a structuring effect on its host territory and future events.

To account for this situation in geographical terms, we can use the concept of "hyper-place" as recently developed by French geographer Michel Lussault (2017) to oppose Marc Augé's (1992) characterisation of the airport as "non-place," reflecting the homogenisation of the world. For Lussault (2017), airports have been poorly observed and described and they must be, on the contrary, conceived-with their heterogeneous population of travellers and workers, their shopping areas, their connections and tensions-as exemplary places of the "hyper-spatiality" (Lussault, 2017) of contemporary work, mixing accessibility, co-presence, and virtual connections.
According to Lussault (2017), the paragon of such "hyper-places" is Times Square as : 1) it is "intense," not only in terms of the diversity of "activities and realities" assembled but also in term of interactions; 2 ) it illustrates "hyper-spatiality" (Lussault, 2017), i.e., it articulates the three central aspects of space: access (the question of mobility, that is, one needs to go there), co-presence (one needs to experiment it, find its place), and connection (to be there is also to communicate with other places); 3) due to its hyperspatiality, Times Square is also "multi-scalar" (Lussault, 2017): through its multiple connections, it is simultaneously a "local, regional, national, world" place but also its "well delimited space inscribes itself into an undefined communicational outer-space"; 4) it actively participates in the experiential dimension of social and spatial practices, i.e., of the cognitive, emotional, and volitive experience of the situated body; and 5) finally, it produces a spatial affinity between all the people that came to experience it, building up a specific form of commoning. We argue that those different characteristics apply to the situation of large events. Hence a 'large' event is not a quantitatively 'big' events but rather an event that transforms not only the spatialities, but also the temporalities of the place where it occurs. Its 'size' matters, but relatively to the size of its host environment or its capacity of absorption as in the case of the Montreux Jazz Festival doubling the population of the city during its performance.

The event's rhythmanalysis can, therefore, be understood as an attempt to concisely comprehend the different spatiotemporal patterns within which the event's performance and resonance occur. It is more broadly part of the procedural approaches of the city stressing the multiple temporalities that compose it (Antchak, 2018; Crang, 2001). As Henry Lefebvre (1992) suggests, it is the intertwining of rhythms that give different cities their spatial dimension and their uniqueness. More fundamentally, we should consider that rhythms constitute themselves within a spatialisation-or better a linking and scaling-process. From this perspective, the urban analysis of large events requires us to consider their spatial dimension from a set of what we can call 'rhythmic scales.' We organise our demonstration around two groups of rhythmic scales which account for the structuration of any urban order.

First, we analyse historical rhythmic scales, corresponding to the historic evolution of the event in terms of length and frequency, size, and spatiality along its resonance over time. Those historical rhythmic scales are essential to understand the genesis of the festival as a 'hyper-place.' Secondly, we propose to consider a performance rhythmic scale linked with the repetitive occurrence of the event. Those are the rhythms and assemblages of Montreux at the time of the Festival. It involves paying attention to the performance of the event, its timings, the influx of people during the evening, or indeed the flows of people in public spaces (congestions, etc.) and the various configurations of actors that are involved 
in its organisation and regulation. Attention must also be paid to the wider modifications of the region and the uses caused by the event.

We need to start visualising those two rhythmic scales to analyse and reflect on the multiple effects of the Montreux Jazz Festival on its urban environment, following up the temporal turn of cartography and space visualisation techniques.

\section{Case Study: Genesis and Performance of the Montreux Jazz Festival as a Polyrhythmic 'Hyper-Place'}

The genesis and growth of the Montreux Jazz Festival, which celebrated its fiftieth anniversary in 2016, appears to be a good example of the festivalisation of culture over the last few decades. In 1961, Claude Nobs (future founder and director of the Festival), when employed at the Tourist Office, was instructed to help in the collective effort to put Montreux back onto the world map. Because of his work over the years, the Jazz Festival very quickly became internationally renowned and, by the end of the 1960s, was able to draw major artists such as Ella Fitzgerald, Aretha Franklin, Frank Zappa, and Chuck Berry. In 2016, Deep Purple came back to Montreux, 45 years after their debut there in 1971, when the musicians were part of the famous fire at the Montreux Casino. The event that would be inscribed in the Festival's history (and in rock history as well) is told in the legendary song 'Smoke on the Water.' The two faces of the music, immaterial and material, allow such exchanges of energy and inspiration and enabled the development of the Festival into a hyper-place. Before going into the cartographic detail of its spatial expansion, a few more elements allow us to observe the spread of resonances of the Jazz Festival, both locally and internationally (Figure 1).

Between 1968 and 2018, the Montreux Jazz Festival's budget went from $10,000 \mathrm{CHF}$ to $28,000,000 \mathrm{CHF}$. The event now attracts an attendance of around 250,000 people over the two weeks it is held. For a city of around 25,000 inhabitants, it means that during 16 days, its pop- ulation is increased daily by $60 \%$, hence the importance of a rhythmic regulation of the arrival and circulation of this public. The visual and material traces that broaden the presence and impact of the Festival to the rest of the world are many and go beyond the music alone. They run from the festival's logo printed on Coca-Cola bottles to the Montreux Jazz Café franchise, managed from Montreux by Montreux Jazz International.

The Montreux Jazz Café restaurants appear as real ambassadors of the Festival's spirit across the world. Yesterday in Paris and London; today in Montreux, Lausanne, Geneva, Zurich, and Abu Dhabi.

The Festival's resonance in Switzerland can also be seen through its attractions area. As shown in Figure 2, the Festival's attraction area reaches all of Switzerland. The spectators' origin is nevertheless unequal. The Festival appears as an event aimed at residents of larger cities, the main consumers of culture in Switzerland (Figure 3). However, the analysis is more complex since regional proximity is also added to the urban dimension. The density of participants by place of residence thus shows four main polarities in terms of spectators' origins. The first centre is peripheral: Zurich. The second two centres are regional and are situated in the Leman metropolis (Geneva and Lausanne). The fourth centre is local, corresponding to Montreux and its surroundings. This hierarchy of centres and the origin of the flows of participants suggest, on the one hand, that the Festival receives spectators from far away and on the other hand, that they are mainly from quite close by. The distribution of participants according to where they are from (Figure 4) confirms this observation. Indeed, $70 \%$ of participants live in the Leman region. The large flow of participants who come from all over Switzerland and, to a certain extent, from abroad, suggests that the Festival benefits from a large breathing space. Apart from media and commercial resonances, the coming together of these people and the regions that they represent physically contribute to the hyper-place of the Festival as a gathering place for people coming from both very close and very far.
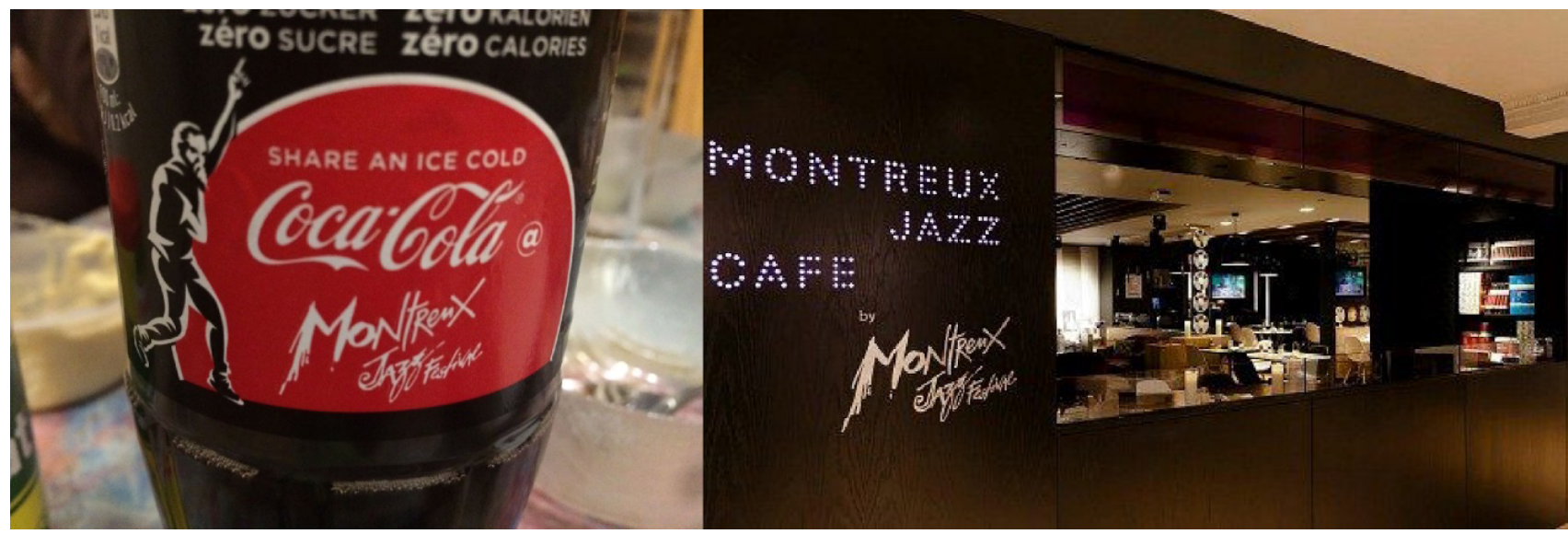

Figure 1. Bottle of Montreux Jazz Festival Coca-Cola (left) and the Montreux Jazz Café at Geneva airport (right). 


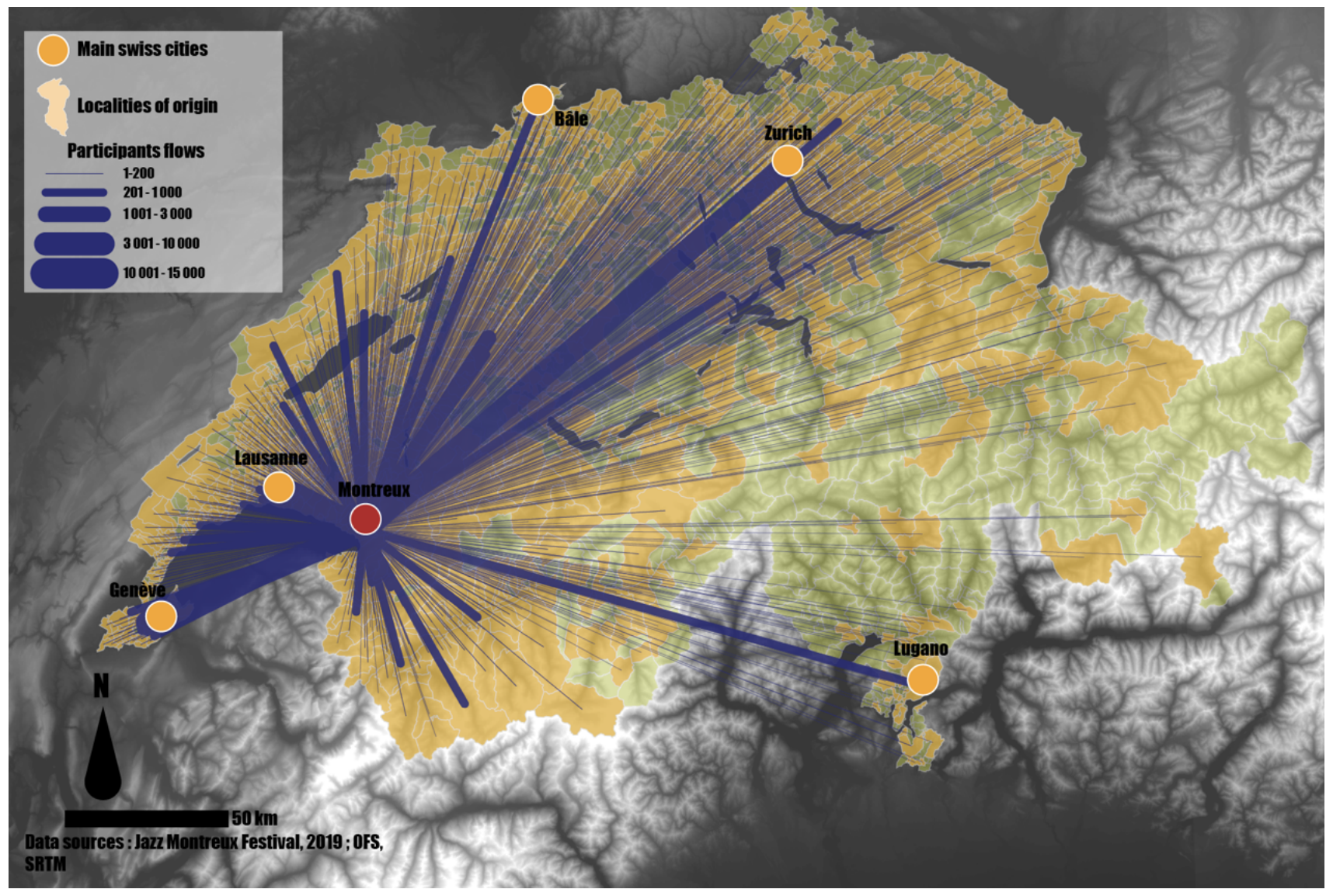

Figure 2. Cartography of the flows of participants to their place of origin. Source: Drevon, Pattaroni, Romany, \& Delley (2019).

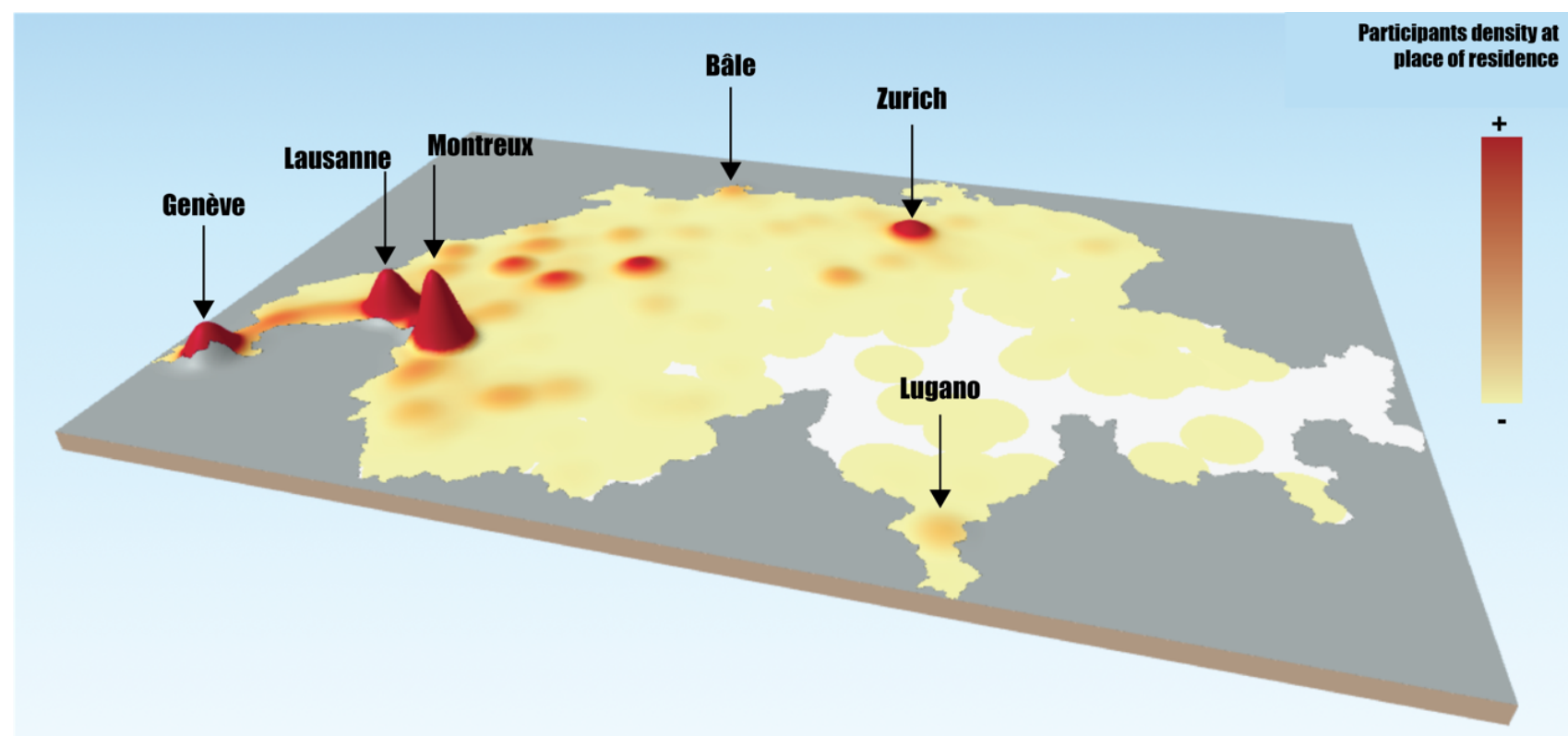

Figure 3. Three-dimensional visualisation of the density of participants by their place of origin. Source: Drevon et al. (2019). 


\section{COGITATIO}

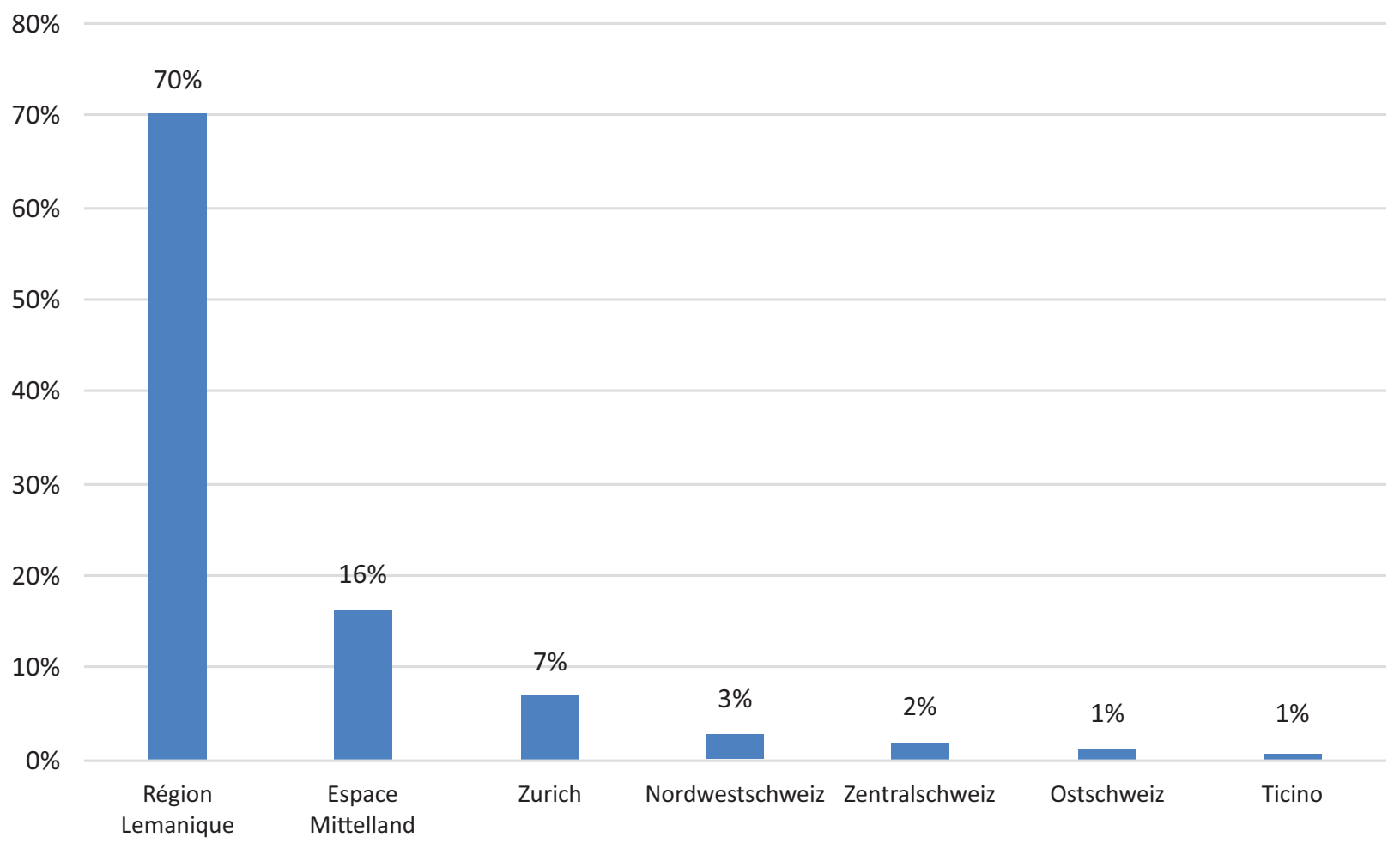

Figure 4. Distribution of participants according to the region of origin. Source: Montreux Jazz Festival (2019).

\section{Data and Methodology}

The methodological challenge raised by the analysis of rhythmic scales of the Montreux Jazz Festival requires the pooling of historical data-knowledge of experts about the festival's history and data about the performance of the event. This research perspective implies, therefore, the implementation of a mixed methodology of data collection (Bergman, 2008; Teddlie \& Tashakkori, 2009).

\subsection{Data}

Data collection and analyses were carried out in the spring of 2019. The data collection methodology used in this research is based on the principle of triangulation between the three sources (archives and interviews, ticketing data, and transaction data of information). The triangulation is commonly used in the social sciences to ensure complementarity between collected data and crossfertilisation (Alavi, Archibald, McMaster, Lopez, \& Cleary, 2018; Denzin, 2017; Frias \& Popovich, 2020). In the social sciences, this approach offers multiple perspectives concerning the object of research, which can thus be observed from different angles. In the context of this article, this multi-perspective approach makes it possible to analyse historical and performance rhythmic scales together. Indeed, the objective of the adopted approach in the analysis is to collect data that reinforce each other in order to reduce analytical uncertainties (Bergman, 2008). Data collection is structured by the previously mentioned rhythmic scales. The two orders of data were diversely collected and then originally cross-referenced. The collection of data about the Festival's historical development tended to bring together elements relating to the evolution of the Festival's influence within Montreux, especially since the 1990s. It was based on the Festival archives and press analysis along semi-structured interviews with stakeholders, allowing the spatial and temporal composition of the festival to be retraced over the last thirty years. The analysis of the archival documentsespecially the complete set of festival programmesmade it possible to reconstruct the location of the festival's stages and the programming of the various concerts and events. The data collection allowed the location of the paid and free-access stages to be differentiated. Interviews with experts were particularly helpful to validate the data collected and understand the grip of certain localisations. The experts allowed the collection of supplementary information on the evolution of security and mobility arrangements put in place to welcome and manage the public. For this reason, the experts interviewed were selected on the basis of their organisational and safety skills and their experience concerning the organisation of the Montreux Jazz Festival (Table 1).

Archives and interviews analysis enabled the creation of a spatiotemporal database of the stages, integrating their location in Montreux over the period 1990-2019. This first database made it possible to establish the evolution of the Festival's spatial influence, thus enabling us to draw an initial visualisation of the historical rhythmic scale of the Festival.

Performance rhythm analyses are based on two sources of information. The first source is the ticketing 
Table 1. Semi-structured interviews' profiles.

\begin{tabular}{ll}
\hline$N^{\circ}$ & Stakeholders functions profile \\
\hline 1 & Municipals heads of departments (authorities) \\
2 & Socials workers in charge of urban mediation \\
3 & Chief of the Police \\
4 & Security partners of the Montreux Jazz Festival (fireman, medical staff, etc.) \\
5 & Organisation members of the Montreux Jazz Festival (permanent office and staffs) \\
\hline
\end{tabular}

data that shows the rhythm of the audience's entry to the Festival venue from ticket scanning. The ticket scanning data was provided to the research team by the festival organising committee. These data allow us to know the exact time and place of entry at the different stages of the festival. From the analysis of these data, it is possible to put into perspective the rhythms of attendance at the different festival stages and thus to measure the rhythmic intensity of the festival in terms of attendance and co-presence. However, these data give a partial view of the attendance by reflecting only access to the festival's paying stages. It is for this reason that a second database of commercial transactions was used to analyse attendance patterns outside of the paid-access stages. Similar to ticket scanning data, commercial transaction data offers the possibility to measure attendance rhythms outside of pay-access stages. This data reveals the location and timing of various commercial transactions, particularly food and drink purchases. By using this data in addition to the ticket scanning data, the overall analysis gives a more complete picture of the reality of the festival's attendance rhythms.

The data collected in the course of the research made it possible to build an original and diversified corpus of information on both the historical and performative rhythms of the festival. This mixed methodological approach and the triangulation system made it possible to improve the quality of the data collected and to propose the most robust possible basis for analysis. However, several limitations must be considered. First of all, the confirmed cross-referencing between the analysis of the archives and the interviews conducted with the experts does not necessarily guarantee the exhaustiveness of the census of the different festival stages. The second cross-reference between the data from ticket scanning and commercial transactions only provides a trace of the passage and only very partially reflects the reality of the rhythms of the attendances at the different places of the festival.

\subsection{Data Analysis}

The methodology of the analysis is based, on the one hand, on spatial analysis, that is, the spatiotemporal visualisation of data collected from the archives of Montreux Jazz Festival; on the other hand, it is also based on the statistical analysis of ticketing and transaction data (cyclic rhythms). The first analysis of the historical rhythmic scales of the Montreux Jazz Festival uses the technique of standard ellipses of variability (Gong, 2002; Kent \& Leitner, 2007; Raine, 1978) to understand the evolution of the Festival stages' dispersion (1990-2010), and to put the spaces influenced by the different performances into perspective. In addition to the spatial analysis, an initial spatiotemporal visualisation was produced based on Time Machine. The Time Machine tool is based on a discretisation of space and time that is used to drive the data storage and access (Kaplan, 2013). It follows that geographical information is organised and stored according to both space and time dimensions (Hamel, 2020).

In order to bring data in the tool, the geographical information needs to be associated with a precise time value before to be imported. This leads to a 4D approach for data management and storage. The tools also come with a 3D interface that addresses spatio-temporal queries to the storage of the data in order to retrieve the required information to build a $3 D$ representation of the geographical information at a given position in time. The interface allows browsing the 3D representation through space similarly to Google Earth, but also allows changing the position in time, creating a new 3D representation. By considering a predefined spatio-temporal trajectory, the tools allow to create a dynamic visualisation of the evolution in time of the geographical information. As a result, any data coming with both geographical footprints and a precise time code can be considered through the tool to create a 4D visualisation of their evolution regardless of their rhythm and geographical description.

The data considered in the visualisation attempt using the Time Machine tool are the geographical footprints of the Montreux Jazz Festival. For each year, the Festival footprint is described in geographical terms and associated to its year time code. The footprints are then imported in the tool. In addition, a wireframe representation of the Swiss geography and topography is also imported to obtain a context in which the footprints can be interpreted. To create the visualisation, a spatiotemporal trajectory is defined around Montreux city in space and spanning from the year 1990 to the year 2019. The obtained visualisation then shows the evolution of the Festival's geographical footprint on the studied time range.

The analysis of the performance rhythmic scales that occur during the Festival is based on the ticketing and transaction data. The times at which tickets were scanned and drinks were ordered were analysed in par- 
allel, to measure the different rhythmic intensities and their recurrences during the week of the Festival. The analyses were based on descriptive statistical techniques from a temporal perspective. Thus, the analysis focuses on identifying the periods of the day and week when the attendance intensity is greatest.

\section{Results and Discussion}

\subsection{Analysis of Historical Rhythmic Scales: Spatialities of Festival Growth}

The historical rhythmic scale approach corresponds to the evolution of the Festival throughout its history on several spatial levels (scaling). The first level concerns the evolution of the Festival's influence and more particularly the dispersion of stages and event venues within Montreux. The second level refers to the different spaces of the Festival by integrating places such as stages, but also its immediate surroundings, which offer potentials of socialisation, conflict, and common space-time. Three types of analysis were carried out using the spatiotemporal database: on the extent of the Festival's influence; on the nature of the stages; and on the impacted spaces. They demonstrate a wider range in terms of spread (dispersion), openness, and territorial grip, which shows the profoundly spatial nature of the Festival:

- Spread: The first analysis shows, on the one hand, the spread and the dispersion of the Festival sites, and on the other hand, the event's centre of gravity. Figure 5 shows the evolution using the analysis of the years 1990, 2000, and 2019. The results show an extension of the spread and an increase in the dispersion of the event's sites. The Festival's centre of gravity tends to position itself gradually towards the Stravinsky stage.
- Openness: The second analysis (Figure 6) shows the evolution of the financial accessibility that accompanies the Festival's spatial dispersion looking at the extent of free over paying accesses. While confirming the extension of the Festival over the years through the multiplication of the different stages, the codification-paying in orange; free in green-shows that it is closely associated with the reinforcement of the open-access offerings within the Festival. In particular, we note the considerable impact of moving the Festival to the new Palais des Congrès in 1993, which helped to place the Festival in the heart of the city. Indeed, along with this move, the Festival began in 1994 to develop a larger 'off' offering at the city level while extending the reach of its core (which has now become a perimeter with more than 70 food stands and other consumer products). This evolution is typical of the festivalisation of public space, which increased in the 1990s (Cudny, 2016).

- Grip: The third analysis (Figure 7) shows the evolution of the zones affected by the Festival. It takes into account, on the one hand, the dissemination of the zones, but also the progression of their spread depending on the evolution of the location of the event, thus confirming the hypothesis of festivalisation of public space. Using historical data of different Festival sites, there was a first attempt at visualising using the Time Machine tool (Figure 8). It shows the relocation of Festival stages from 1967 to 2019 and confirms the observations made in the previous analysis. By covering a longer time-span and enabling a year-by-year visualisation, the Time Machine tool reveals multiple spatial reconfigurations and the events that affected the spatial organisation of the Festival. For example, the Kursaal Casino, the historical cen-

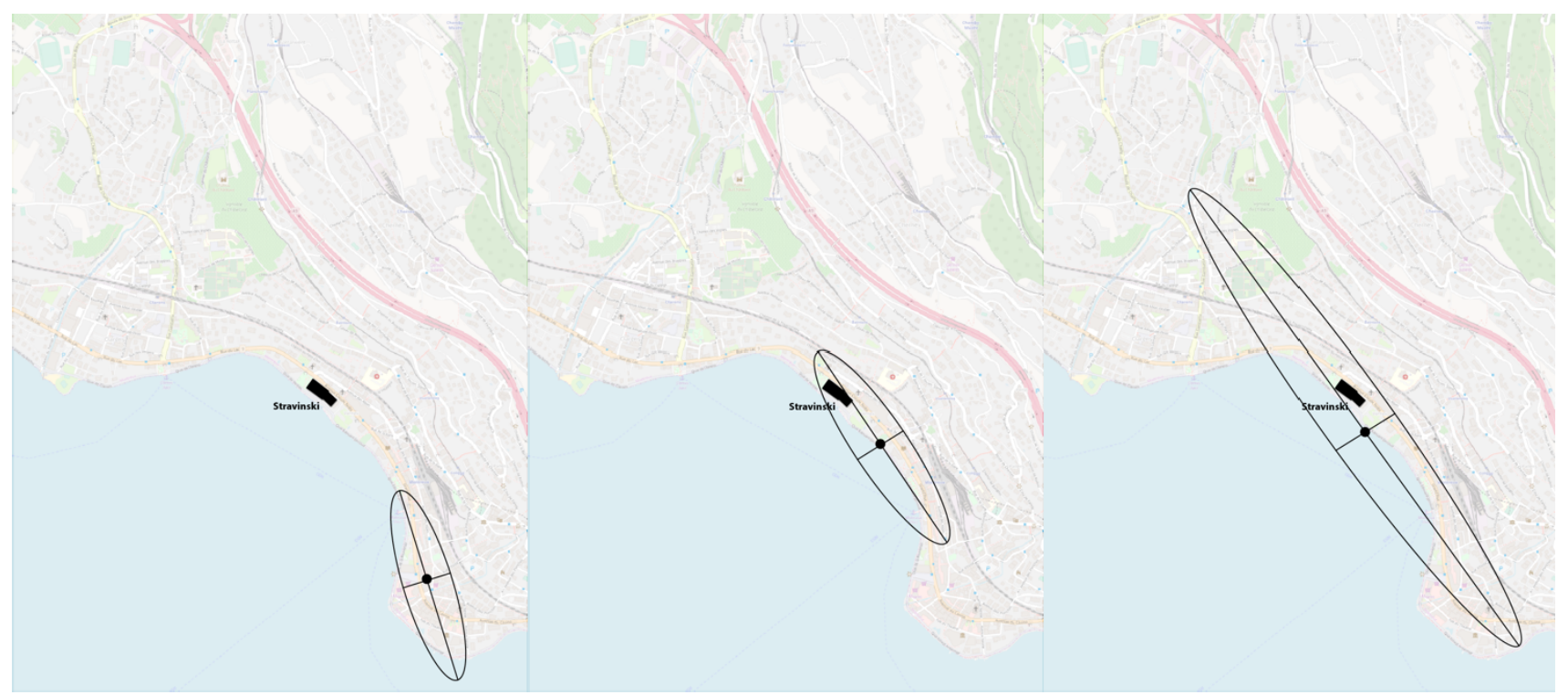

Figure 5. Centro-graphic analysis of the evolution of Festival sites (spread). Note: From left to right: 1990, 2000 , and 2019. 


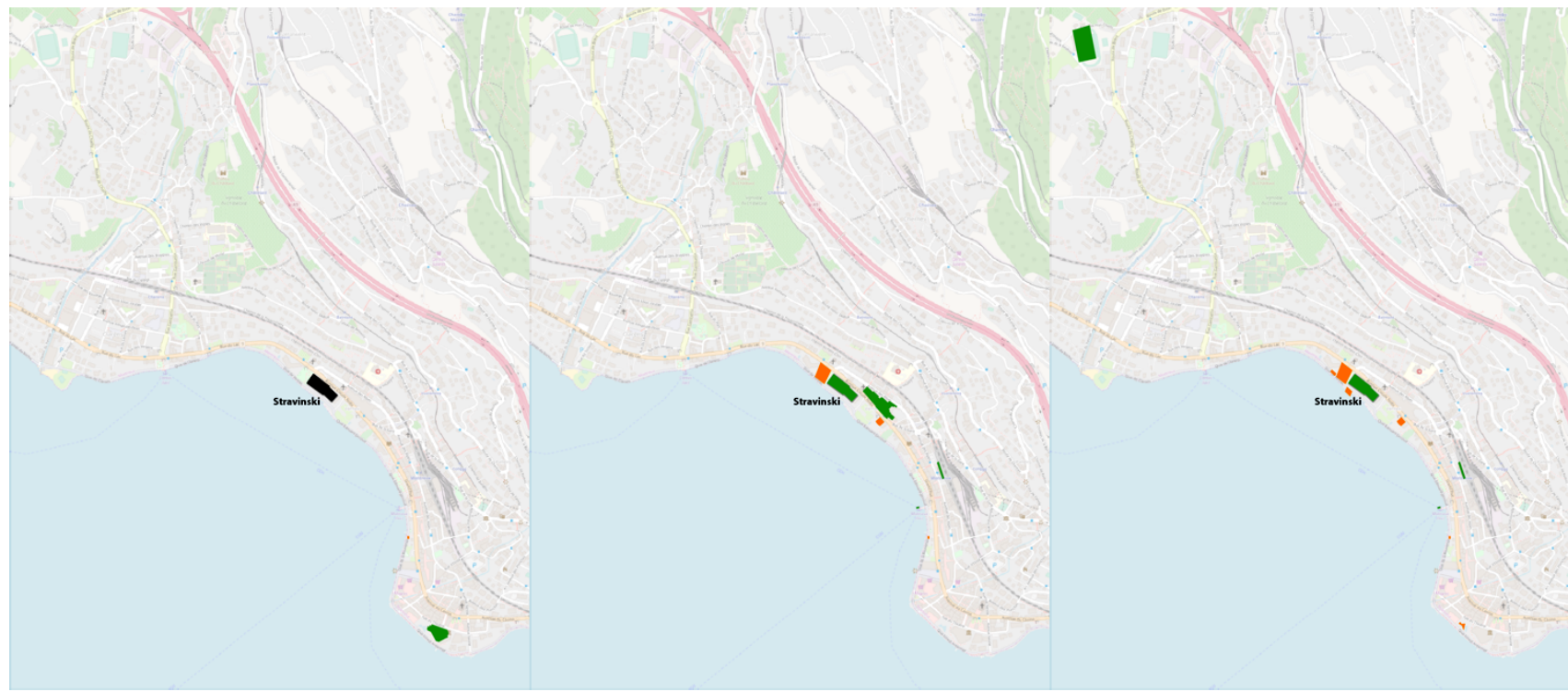

Figure 6. Analysis of the evolution of Festival sites and their access (in green: stages with paid access; in orange: freely accessible stages-openness). Note: From left to right: 1990, 2000, and 2019.

tre of the Festival, had a major fire in 1971 (the one from Deep Purple's song). Following this event, the 1972, 1973, and 1974 editions took place in the Pavilion of Montreux Palace and the Maison des Congrès.

These preliminary analyses show the Festival's progression in terms of spread, site dispersion, and accessibility (free/paying). Analytically, it allows tackling the question of the influence of the Festival on the city. The serie of visualisation isn't a mere visual reconstruction but it represents real transformations of urban spaces and practices. Indeed, the localisation of the festival within the city centre has had a major impact on the way Montreux has developed over the last decade. As sug- gested by geographer Antonio Da Cunha (Arboit, 2016), the "Festival has structured the space and transformed the geometry of the uses and walking habits of its inhabitants all year long." Among others, the main commercial street developed itself between the old and the new centre of the Festival, shifting to the west the city centre in comparison to its earlier development. Investments in the setting of public spaces and parks followed this impulse. This articulation between the Festival development and the city structuration has an impact both on the daily rhythms and the event rhythms, especially linked with commercial activities and pleasure strolling. As the Festival performs in the city centre-that it contributed to delineate-it is now difficult to block the ordinary daily mobility roads to build up the performance

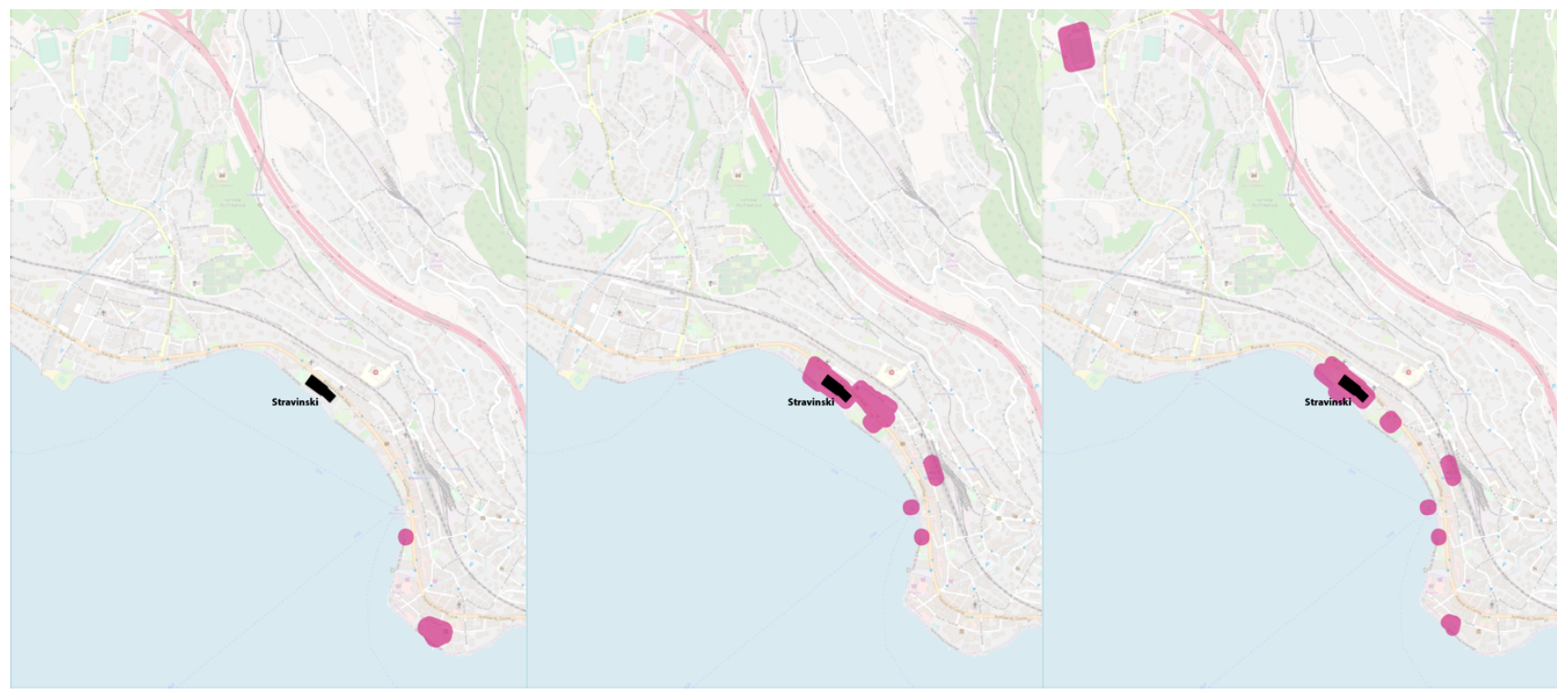

Figure 7. Analysis of the evolution of areas affected by the Festival (territorial grip). Note: From left to right: 1990, 2000, and 2019. 

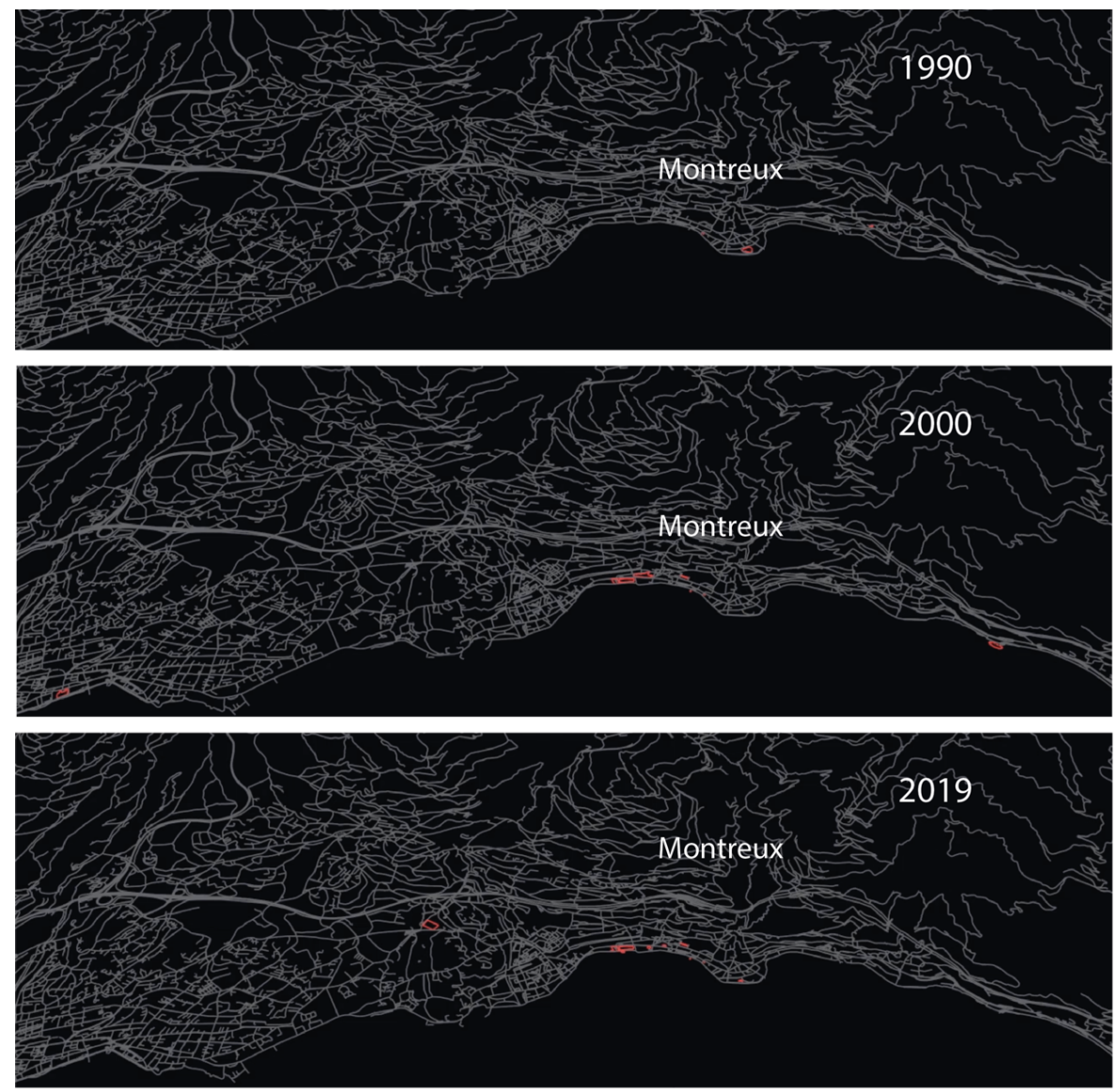

Event places

Figure 8. Visualisation attempt using the Time Machine tool.

spaces of the Festival. The choice of developing the lakeside as the public space of the Festival appears not only as a scenic choice but also as a good compromise with the localisation of the Festival.

At an operational level, the analysis suggests that the spatiotemporal system of the event has become more complex over the years. From this point of view, it is a relevant analysis tool for planners in terms of evaluating and forecasting their regulation systems. Also, the visualisation created using the Time Machine tool also makes it possible to revive the collective memory by highlighting significant events that have influenced the historical rhythms of expansion of the Montreux Jazz Festival.

\subsection{Analysing Performance Rhythms of the Event}

The second result developed in this article refers to the measurement of cyclic rhythms during the Festival held in the summer of 2019. The analyses are primarily based on the ticket scanning carried out by the Montreux Jazz Festival security teams. The scans show the access to the paid-for stages (day, time, and site). Also, the analysis of transaction data relating to the consumption rate of drinks makes it possible to measure the attendance at the free-access Festival venues. This involves bars and restaurants in particular. For this part, and depending on the available data, the analysis focused on the 'Music in the Park' stage. With a capacity of 3,000 and its central position at the heart of the Festival, this venue receives a significant percentage of festival-goers. Therefore, the analysis of transactions made at this establishment gives a relatively representative overview of the Festival's busy periods. The joint analysis of these two sets of data makes it possible to put into perspective the rhythms of the Festival in different time scales: the period of the Festival, weekdays, and weekend days.

Based on the ticket-scanning data (Figure 9), the second analysis shows the average attendance intensity according to the days of the week and weekends during the Festival period. The two curves follow equivalent trends. Indeed, for weekdays and weekend days, the maximum attendance intensity is between 19:15 and 20:00. On average, during this period, about 600 people per hour flock to watch the show. Complementary analyses also show that this rhythmic pattern is repeated throughout the days of the Festival with relatively variable intensities. Behind this variation in intensity is the effect of programming on audience attendance. Fixed-time programming tends to concentrate the audience for a relatively short period on both weekends and weekdays.

The analysis presented in Figure 10 shows the average number of transactions made during the day on 


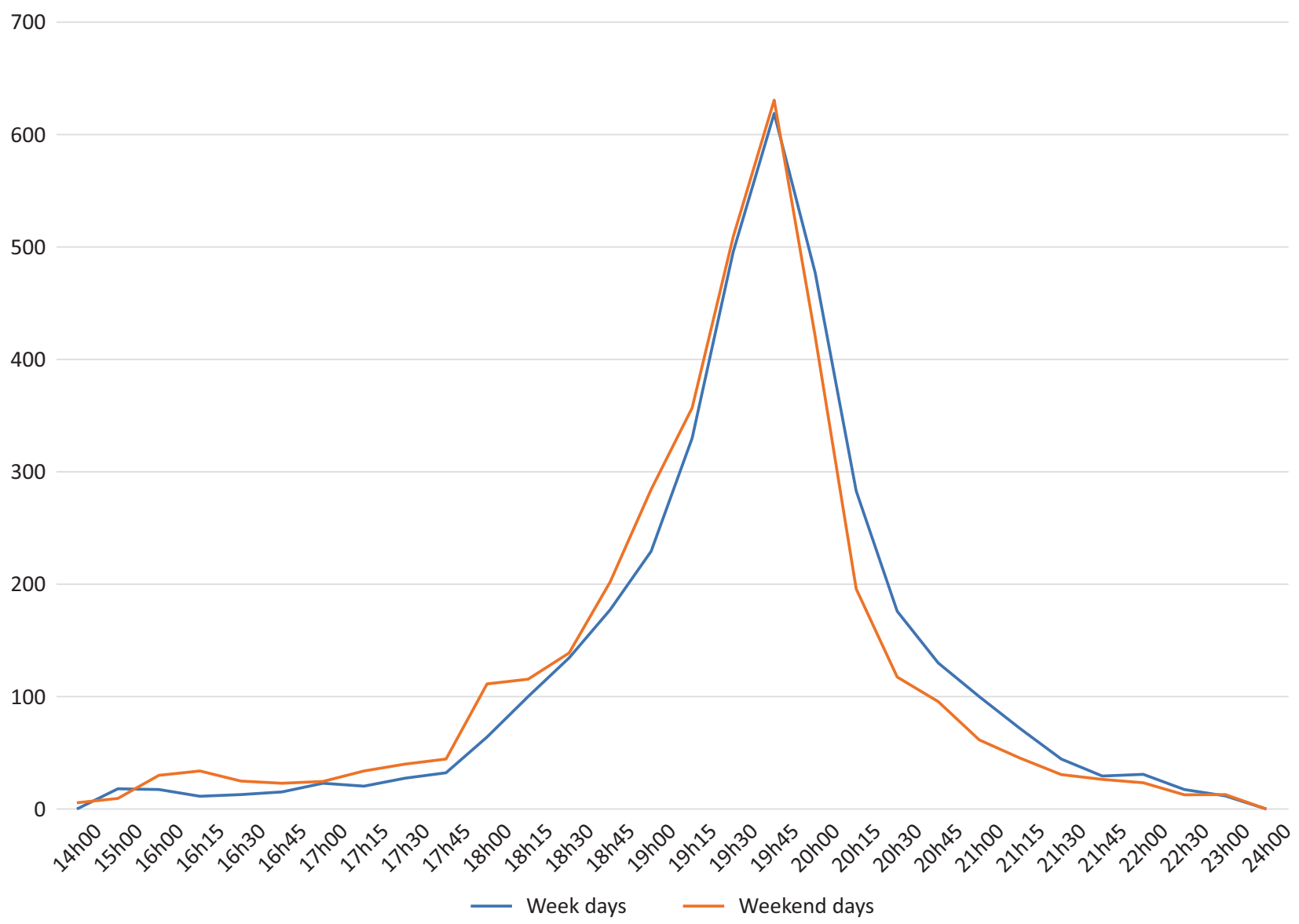

Figure 9. Average attendance according to the time of day (data from ticket scanning).

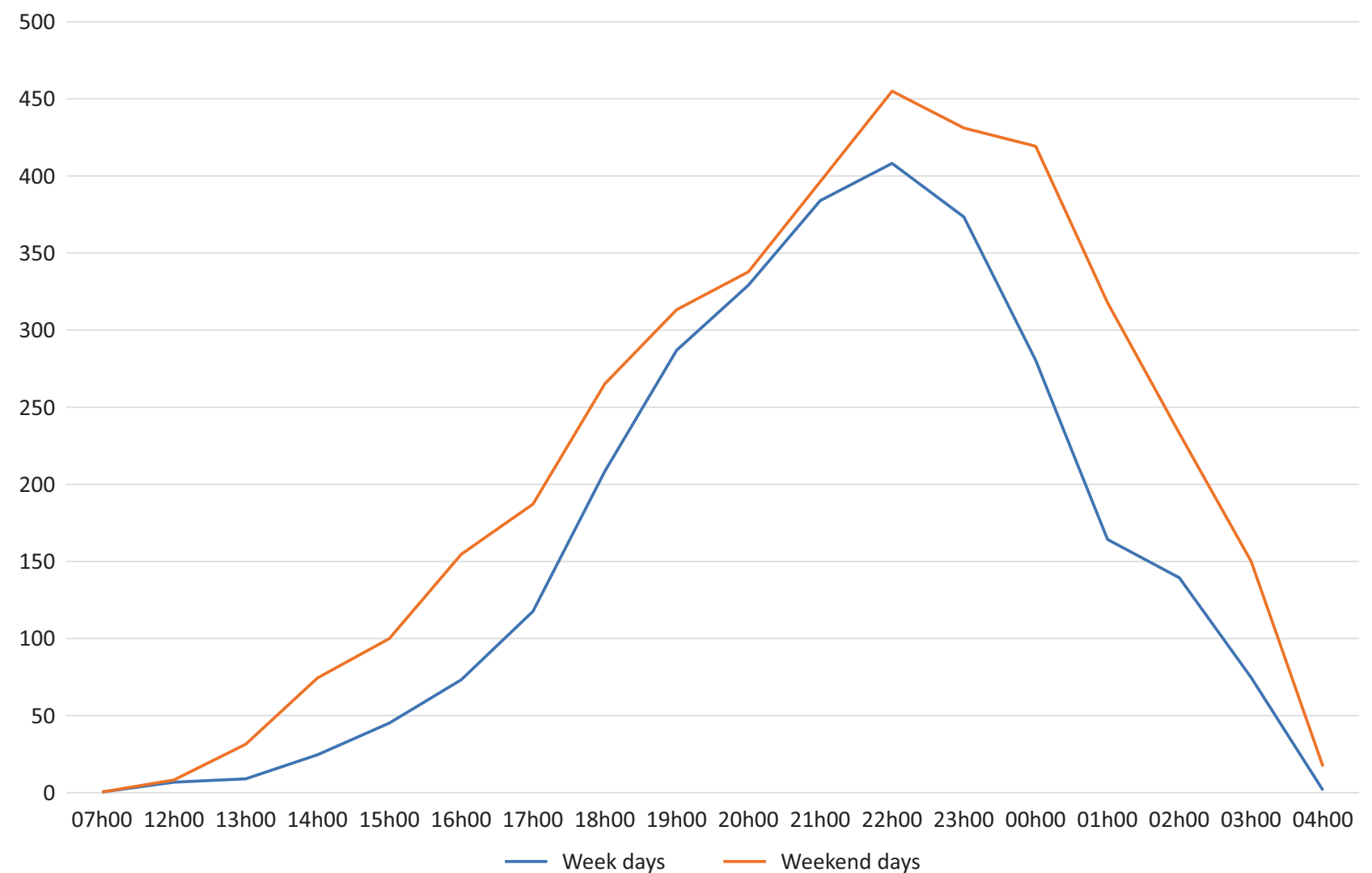

Figure 10. Average number of transactions according to the times of the day. 
900

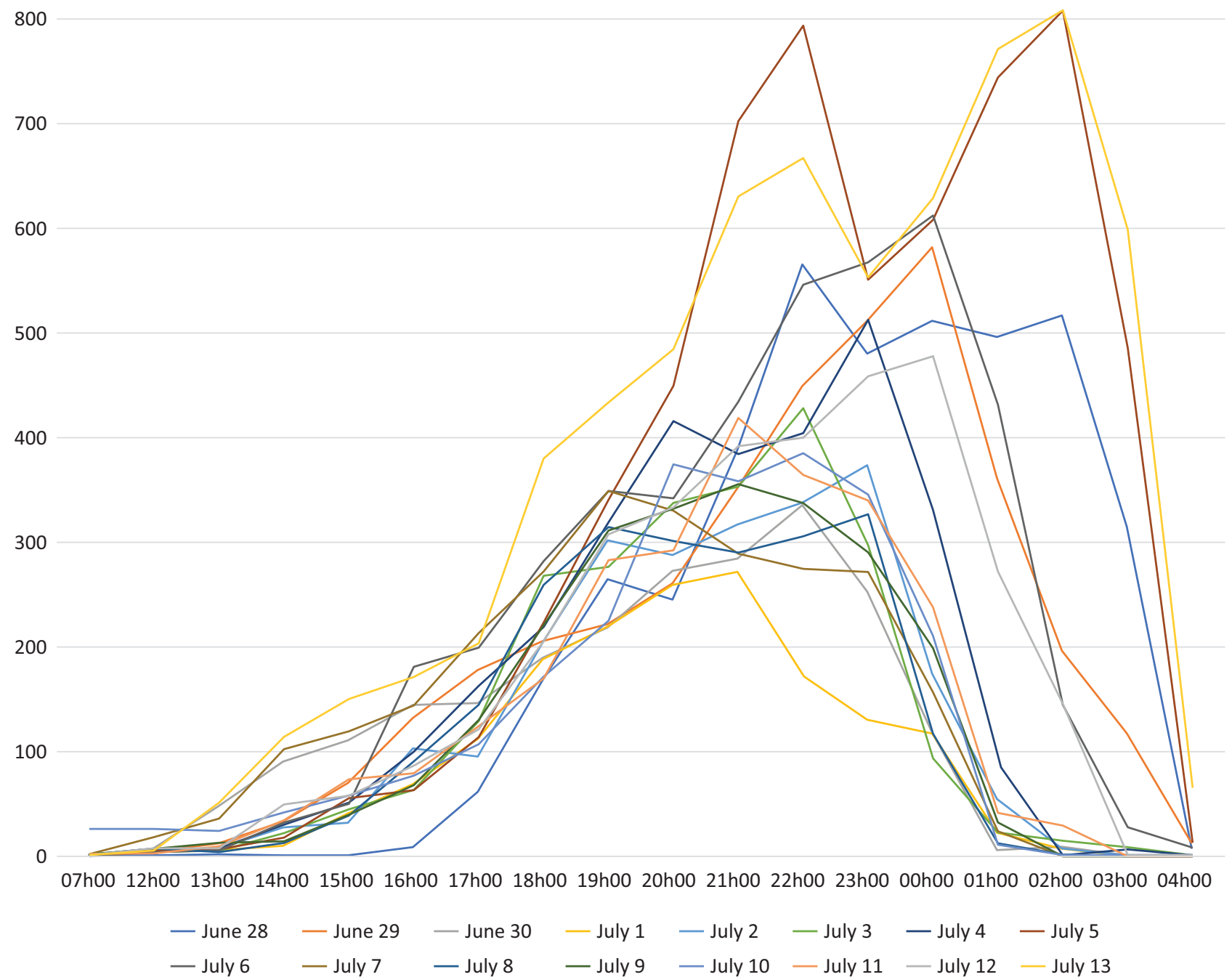

Figure 11. Number of transactions according to the days of the Festival.

weekends and weekdays. The two curves also follow equivalent trends. Compared to the previous analysis, an important contrast is observed. The increase in attendance appears less sudden than in the first analysis. Indeed, the number of transactions increases progressively from about 13:00 and decreases more abruptly from midnight to 1:00. Also, the greatest rhythmic intensity in terms of transactions occurs later during the weekend. This result indicates a more progressive attendance compared to ticket scanning.

Complementary analyses on each of the days of the Festival (Figure 11) show particularly contrasted rhythmic configurations. Even though for all of the days, the progressive growth in the number of transactions tends to start at around 13:00, the rhythmic peaks are more strongly contrasted in their temporal registering and intensity. For example, the days of the 5th (Friday) and the 13th (Saturday) July 2019 have the greatest intensities and the longest temporal spreads. This second ana- lysis confirms the hypothesis of cyclic rhythms that repeat throughout the days of the Festival. However, these rhythmic regularities tend to be more or less intense depending on weekdays or weekends. This differentiation between the week and the weekend invites us to reflect, beyond the effects of programming, on the more fundamental rhythms of the leisure practices of which such Festivals are a part. In fact, programming schedulesand audience practices-do not deviate much from usual weekday or weekend outings. The Festival does not use new rhythmic forms such as, for example, the dawn concerts that take place in summer at the Bains de Pâquis in Geneva.

\section{Conclusion and Discussion}

In this article we followed up recent calls to develop a rhythmanalysis of urban events, shifting away from the sole focus on everyday urban rhythms. Such a rhyth- 
manalysis is necessary to account for the temporary and lasting effects of large events on the spatial and temporal organisation of cities, a question that has become a major concern for urban development (Richards \& Palmer, 2010). As discussed in the first part of the article, this rhythmanalysis is based on the idea that the development and regulation of such events imply active processes of connecting and ordering-in time and space-the various entities engaged in its performance. We consider 'rhythmic scales' as both the process and the outcome of such reconfigurations producing new 'hyperscalar,' 'hyperspatial' and intense urban territories, what the French geographer Michel Lussault (2017) calls "hyper-places." Rhythms appear as an inherent and key feature of the composition of heterogeneous urban assemblages.

The visualisations show the expansion of the concerned territories along the shift of its centrality. Those evolutions had lasting effects on the Montreux urban fabric (re-localisation of its commercial centre, public space rehabilitation, leisure practices), but they are also the reflection of the transformation of the Festival policy as since the 2000s it began to be conceived as a broader open-access public fair where a large part of the public never enters the paying areas. This expansion of the concerned spaces and public lead to other rhythmic performance modifications such as the temporary transformation of the Public Transport offer (night service, increase of the frequency) at the regional but also national level. On a more institutional level, social workers now have to work all night long to monitor teenagers who hang around the event. Along with the fire service, policemen, and special public units, there is a large network of involved actors that are directly paid by the city of Montreux, reflecting the central dimension of the Festival for their branding and touristic policies. The performance rhythmic scale is therefore particularly concerned with how the public has access to the event and takes its place within it. The combined analysis of ticketing and transaction data shows the alternance between high and low-intensity periods. These allowed us to confirm the impact of programming on flows, but also the effects of the wider organisation of the leisure system.

The continuation of this reflection between the rhythms of the Festival and the wider societal rhythms seems essential to us. Indeed, the Festival is part of the twofold framework imposed by the rhythmic scales of work and leisure. Generally speaking, the rhythm and supply of transport in European cities is calculated based on work needs. The challenge for major events is to fit these rhythmic scales into this established framework: adapting the transport supply but also the pedestrian flows. From an operational perspective, the articulation of these different rhythmic scales is central to improving event management, but also to thinking more broadly about the ripple effect of such an event on urban development. The immediate and distant resonance of the event, meaning its power as a hyper-place, is, there- fore, the result of the confluence of different rhythmic issues such as programming, systems for allocating seats for concerts and, more broadly, the organisation of leisure practices. Each of these elements refers to specific performance regimes, and thus require work on the event's rationales, its planning tools, and its regulation devices (Viot et al., 2010). Only an increase in the number of these 'levers' is capable of influencing the rhythmic scales of the Festival and its inclusion in an ideal policy of large events. Urban event policies are thus in urgent need of visualisation tools capable of showing the articulation of the temporal and spatial effects of events and how they produce the renewed scales of the territorial commons.

\section{Acknowledgments}

We would like to thank the Montreux Jazz Festival organisation team for their collaboration and access to the data. We acknowledge also the EPFL-ENAC Habitat Research Center for the project "Habitats In Time, Mapping Palimpsest Horizons" that supported this research.

\section{Conflict of Interests}

The authors declare no conflict of interests.

\section{References}

Alavi, M., Archibald, M., McMaster, R., Lopez, V., \& Cleary, M. (2018). Aligning theory and methodology in mixed methods research: Before design theoretical placement. International Journal of Social Research Methodology, 21(5), 527-540. https://doi. org/10.1080/13645579.2018.1435016

Antchak, V. (2018). City rhythms and events. Annals of Tourism Research, 68, 52-54. https://doi.org/ 10.1016/j.annals.2017.11.006

Antonioli, M., Drevon, G., Kaufmann, V., Gwiazdzinski, L., \& Pattaroni, L. (2020). Manifeste pour une politique des rythmes. Lausanne: PPUR Presses Polytechniques.

Arboit, S. (2016, July 13). Grâce au Jazz, le coeur de Montreux bat entre le Casino et l'antre des concerts. 24heures.ch. Retrieved from https://www.24heures. $\mathrm{ch} / \mathrm{v}$

Axhausen, K. W., Zimmermann, A., Schönfelder, S., Rindsfüser, G., \& Haupt, T. (2002). Observing the rhythms of daily life: A six-week travel diary. Transportation, 29(2), 95-124. https://doi.org/10.1023/A: 1014247822322

Augé, M. (1992). Non-lieux. Introduction à une anthropologie de la surmodernité [Un-places. Introduction to an anthropology of supermodernity]. Paris: Le Seuil.

Bauman, Z. (2013). Liquid modernity. Hoboken, NJ: John Wiley \& Sons.

Bergman, M. M. (2008). Advances in mixed methods research: Theories and applications. London: SAGE. 
Boullier, D. (2015). La ville événement: Foules et publics urbains [The event city: Crowds and urban audiences]. Paris: Presses Universitaires de France.

Brighenti, A. M., \& Kärrholm, M. (2016). Three presents: On the multi-temporality of territorial production and the gift from John Soane. Time \& Society, 28(1), 375-398. https://doi.org/10.1177/ $0961463 \times 16678254$

Brighenti, A. M., \& Kärrholm, M. (2018). Beyond rhythmanalysis: Towards a territoriology of rhythms and melodies in everyday spatial activities. City, Territory and Architecture, 4(1). https://doi.org/10.1186/ s40410-018-0080-x

Callon, M. (1986). Éléments pour une sociologie de la traduction: La domestication des coquilles SaintJacques et des marins-pêcheurs dans la baie de SaintBrieuc [Elements for a sociology of translation: The domestication of scallops and fishermen in the Bay of St. Brieuc]. L'Année Sociologique (1940/1948-), 36, 169-208.

Crang, M. (2001). Rhythms of the city: Temporalised space and motion. In J. May \& N. Thrift (Eds.), Timespace: Geographies of temporality (pp. 187-207). Abingdon: Routledge. Retrieved from http://www. routledge.com/9780415180832

Cudny, W. (2016). Festivalisation and its effects on the urban space. In W. Cudny (Ed.), Festivalisation of urban spaces: Factors, processes and effects (pp. 77-117). Cham: Springer. https://doi.org/10.1007/978-3-31931997-1_4

Denzin, N. K. (2017). The research act: A theoretical introduction to sociological methods. London: Transaction Publishers.

Drevon, G., Pattaroni, L., Romany, T. P. L., \& Delley, L. (2019). Rythmologie d'un hyper-lieu. Le cas du Montreux Jazz festival [Rhythmology of a hyper-place. The case of the Montreux Jazz festival]. EPFL. Retrieved from http://infoscience.epfl.ch/record/267695

Drevon, G., Kaufmann, V., \& Gerber, P. (in press). Dealing with long commuting and daily rhythms. Sustainability. Advance online publication.

Edensor, T. (2012). Geographies of rhythm: Nature, place, mobilities and bodies. Farham: Ashgate Publishing.

Edensor, T., \& Larsen, J. (2018). Rhythmanalysing marathon running: 'A drama of rhythms.' Environment and Planning A, 50(3), 730-746. https://doi. org/10.1177/0308518X17746407

Ellegård, K., \& Vilhelmson, B. (2004). Home as a pocket of local order: Everyday activities and the friction of distance. Geografiska Annaler: Series B, Human Geography, 86(4), 281-296. https://doi.org/10.1111/j.04353684.2004.00168.x

Flemsæter, F., Gundersen, V., Rønningen, K., \& Strand, O. (2019). The beat of the mountain: A transdisciplinary rhythmanalysis of temporal landscapes. Landscape Research, 44(8), 937-951. https://doi.org/10.1080/ 01426397.2018 .1535652

Frias, K. M., \& Popovich, D. (2020). An experiential ap- proach to teaching mixed methods research. Journal of Education for Business, 95(3), 193-205. https:// doi.org/10.1080/08832323.2019.1627995

Gong, J. (2002). Clarifying the standard deviational ellipse. Geographical Analysis, 34(2), 155-167. https:// doi.org/10.1111/j.1538-4632.2002.tb01082.x

Hallin, P. O. (1991). News paths for time-geography. Geografiska Annaler. Series B, Human Geography, 73(3), 199-207.

Hamel, N. (2020). Nils-hamel/eratosthene-suite. GitHub. Retrieved from https://github.com/nils-hamel/ eratosthene-suite

Hassan, R. (2007). 24/7: Time and Temporality in the network society. Palo Alto, CA: Stanford University Press.

Kaplan, F. (2013). How to build an information time machine. Infoscience. Retrieved from https:// infoscience.epfl.ch/record/225504

Kärrholm, M. (2007). The materiality of territorial production: A conceptual discussion of territoriality, materiality, and the everyday life of public space. Space and Culture, 10(4), 437-453. https://doi.org/ $10.1177 / 1206331207304356$

Kent, J., \& Leitner, M. (2007). Efficacy of standard deviational ellipses in the application of criminal geographic profiling. Journal of Investigative Psychology and Offender Profiling, 4(3), 147-165. https:// doi.org/10.1002/jip.72

Klein, O., Drevon, G., \& Gwiazdzinski, L. (2017). Représenter les temps et les rythmes urbains [Representing urban rhythms]. In G. Drevon, Gwiazdzinski, \& O. Klein (Eds.), CHRONOTOPIES: Lecture et écriture des mondes en mouvement [CHRONOTOPICS: Reading and writing on a world in movement] (pp. 72-81). Grenoble: Elya. Retrieved from https://infoscience.epfl.ch/ record/232599

Kristensen, M. L. (2018). Mindfulness and resonance in an era of acceleration: A critical inquiry. Journal of Management, Spirituality \& Religion, 15(2), 178-195. https://doi.org/10.1080/14766086.2017.1418413

Launay, J., Tarr, B., \& Dunbar, R. I. M. (2016). synchrony as an adaptive mechanism for large-scale human social bonding. Ethology, 122(10), 779-789. https://doi. org/10.1111/eth.12528

Leary-Owhin, M. E., \& McCarthy, J. P. (2019). The Routledge handbook of Henri Lefebvre, The city and urban society. Abingdon: Routledge.

Lefebvre, H. (1974). La production de l'espace [The production of space]. L'Homme et la Société, 31(1), 15-32. https://doi.org/10.3406/homso.1974.1855

Lefebvre, H. (1992). Éléments de rythmanalyse: Introduction à la connaissance des rythmes. Paris: Éditions Syllepse.

Lenntrop, B. (1976). Paths in space-time environments: A time-geographic study of movement possibilities of individuals. Lund: Royal University of Lund, Department of Geography.

Lussault, M. (2017). Hyper-lieux: Les nouvelles géographies de la mondialisation [Hyper-places: The new ge- 
ographies of globalization]. Paris: Le Seuil.

Mareggi, M. (2013). Urban rhythms in the contemporary city. In D. Henckel, S. Thomaier, B. Könecke, R. Zedda, \& S. Stabilini (Eds.), Space-time design of the public city (pp. 3-20). Dordrecht Heidelberg: Springer. https://doi.org/10.1007/978-94-007-6425-5_1

McCormack, D. P. (2014). Refrains for moving bodies: Experience and experiment in affective spaces. Durham, NC: Duke University Press.

McFarlane, C. (2011). Assemblage and critical urbanism. City, 15(2), 204-224. https://doi.org/10.1080/ 13604813.2011 .568715

Mels, T. (2016). Reanimating places: A geography of rhythms. Abingdon: Routledge.

Pradel, B. (2010). Rendez-vous en ville! Urbanisme temporaire et urbanité évènementielle: Les nouveaux rythmes collectifs [See you in town! Temporary urban planning and urban events: The new collective rhythms] (Doctoral dissertation). Université Paris-Est, Paris, France. Retrieved from https://tel.archivesouvertes.fr/tel-00546513

Pred, A. (1977). The choreography of existence: Comments on Hägerstrand's time-geography and its usefulness. Economic Geography, 53(2), 207-221. https://doi.org/10.2307/142726

Raine, J. W. (1978). Summarizing point patterns with the standard deviational ellipse. Area, 10(5), 328-333.

Richards, G., \& Palmer, R. (2010). Eventful cities: Cultural management and urban revitalisation. London: Routledge. https://doi.org/10.4324/9780080940960
Rosa, H. (2013). Social acceleration: A new theory of modernity. New York, NY: Columbia University Press.

Rosengren, C. (2019). Performing work: The drama of everyday working life. Time \& Society, 28(2), 613-633. https://doi.org/10.1177/0961463X15620983

Simpson, P. (2008). Chronic everyday life: Rhythmanalysing street performance. Social \& Cultural Geography, 9(7), 807-829. https://doi.org/10.1080/ 14649360802382578

Teddlie, C., \& Tashakkori, A. (2009). Foundations of mixed methods research: Integrating quantitative and qualitative approaches in the social and behavioral sciences. London: SAGE.

Thévenot, L. (1984). Rules and implements: Investment in forms. Social Science Information, 23(1), 1-45. https://doi.org/10.1177/053901884023001001

Viot, P., Pattaroni, L., \& Berthoud, J. (2010). Voir et analyser le gouvernement de la foule en liesse: Eléments pour l'étude des rassemblements festifs à l'aide de matériaux sonores et visuels [Seeing and analyzing the government of the jubilant crowd: Elements for the study of festive gatherings using audio and visual Materials ]. ethnographiques.org, 2010(21). Retrieved from https://serval.unil.ch/notice/serval: BIB_A79950B8CAB9

Viry, G., Ravalet, E., \& Kaufmann, V. (2015). High mobility in Europe: An overview. In G. Viry \& V. Kaufmann (Eds.), High mobility in Europe (pp. 29-58). https:// doi.org/10.1057/9781137447388_3

\section{About the Authors}

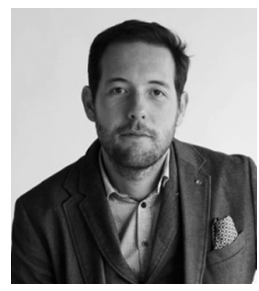

Guillaume Drevon (PhD) is a Geographer. He is developing his research at the Urban Sociology Lab of Swiss Federal Institute of Technology Lausanne. His researches focus on life rhythms. Dr. Guillaume Drevon develops new conceptual frameworks and methods to analyse urban rhythms. He is currently developing the concept of rhythmology to analyse contemporary mobilities and societies. He has recently published ten articles about life rhythms, a book about rhythmology, and three co-edited books concerning urban rhythms.

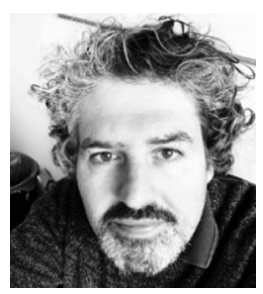

Luca Pattaroni (PhD) is a Sociologist and Senior Scientist at the Laboratory of Urban Sociology of the EPFL where he leads the research group "City, Habitat and Collective Action". He has been a Visiting Professor at the Federal University of Rio de Janeiro and a Visiting Scholar at the University of Columbia. $\mathrm{He}$ is a Board Member of the Swiss Journal of Sociology and of Articulo, The Journal of Urban Research. His work is concerned with the expression of differences and the making of the common in contemporary capitalist cities.

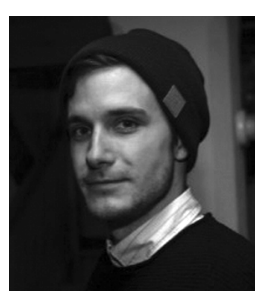

Lucien Delley, first a Social Worker and then a Sociologist, is the Security Coordinator of the Montreux Jazz Festival and a PhD Student at the Laboratoire de Sociologie Urbaine (LaSUR-EPFL). His research focuses on social, spatial, and political issues related to the increasingly valued festive use of the contemporary city. In parallel, he teaches "Prevention and Risk Reduction in Festive Environments" at the Geneva University of Social Work (HETS). He is also a founding member of iSSUE (Swiss Institute for Urban and Event Security). 


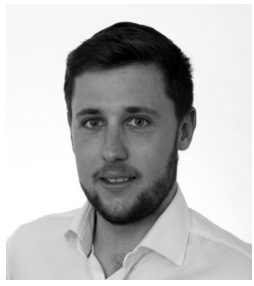

Fabien Javot-Descombes is about to finish his master's degree in transportation and mobility at the Ecole Polytechnique Federale de Lausanne (EPFL). During his last semesters, he has had the chance to specialise in the field of transport planning for major events, and collaborate on diverse projects with the Urban Sociology Lab. In addition, he is also involved in the operations of the Montreux Jazz Festival, being in charge of the information/customer care sector.

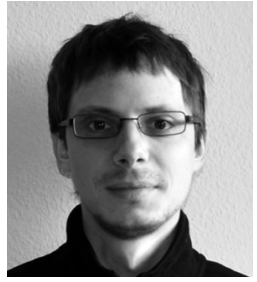

Nils Hamel works as a research engineer at the Digital Humanities laboratory (DHLAB-EPFL). His research focuses on 4D mapping and 4D information systems for large collection of models coming from various sources. He also works on the "ScanVan" project as a engineer developing a spherical camera able to produce 3D model from panoramic images. 